\title{
Erratum to: Gastrointestinal Dysfunction in a Parkinson's Disease Rat Model and the Changes of Dopaminergic, Nitric Oxidergic, and Cholinergic Neurotransmitters in Myenteric Plexus
}

\author{
Hong Can Zhu • Jing Zhao • Chang Yue Luo • \\ Qian Qian Li
}

Published online: 25 February 2012

(C) Springer Science+Business Media, LLC 2012

\section{Erratum to: J Mol Neurosci \\ DOI 10.1007/s12031-011-9560-0}

The original version of this article unfortunately contained a mistake. The change is underlined as follows.

\section{Discussion}

Enteric dopaminergic neurons represent only a small portion of enteric neurons, and enteric non-dopaminergic neurons could also be damaged during the progression of PD (Zhu et al. 2011; Zhao et al. 2011).
Acknowledgments We are grateful to Jinxia Zhu for her guidance in this experiment. We thank the Departments of Anatomy and Pharmacology at Basic Medical College of Zhengzhou University for kindly providing laboratory instruments and animal rooms. We are grateful to the Experimental Animal Center at Zhengzhou University for providing experimental animals.

\section{References}

Zhu HC, Zhao J, Zhang H, Luo CY, Li QQ, Ren XH, Zang WD (2011) Mechanism of gastro intestinal dysfunction in rats with Parkinson disease. J Clin Neurol 24(3):202-205

Zhao J, Guo GH, Zang WD, Zhang H, Luo CY, Li QQ (2011) Gastrointestinal dysfunction and nitric oxide changes of myenteric plexus in a rodent model of Parkinson's disease. J Apoplexy Nerv Dis 28(7):597-600
The online version of the original article can be found at http://dx.doi. org/10.1007/s12031-011-9560-0.

H. C. Zhu $(\bowtie) \cdot$ J. Zhao $\cdot$ C. Y. Luo $\cdot$ Q. Q. Li

Department of Neurology,

the First Affiliated Hospital of Zhengzhou University,

Zhengzhou 450052, China

e-mail: zhc660407@hotmail.com 